BMJ Open Sport \& Exercise Medicine

\section{Prevalence of drop-out from organised extracurricular sports and associations with body fat percentage during childhood and adolescence}

To cite: Vella SA,

Schweickle MJ, Sutcliffe JT. Prevalence of drop-out from organised extracurricular sports and associations with body fat percentage during childhood and adolescence. BMJ Open Sport \& Exercise Medicine 2020;6:e000751. doi:10.1136/ bmjsem-2020-000751

Accepted 3 May 2020
Check for updates

(C) Author(s) (or their employer(s)) 2020. Re-use permitted under CC BY-NC. No commercial re-use. See rights and permissions. Published by BMJ.

${ }^{1}$ Early Start Research Institute. Global Alliance for Mental Health in Sport, University of Wollongong, Wollongong, New South Wales, Australia

${ }^{2}$ School of Psychology. Global Alliance for Mental Health in Sport, University of Wollongong, Wollongong, New South Wales, Australia

Correspondence to Dr Stewart A Vella; stvella@uow.edu.au

\section{ABSTRACT}

Objectives This paper aimed to report the prevalence of drop-out from organised sports between the ages of 10 and 14 years, and to examine potential associated detriments to levels of body fat.

Methods All data were drawn from waves 4-6 of the Longitudinal Study of Australian Children. Participants' sport participation was parent reported and body fat percentage was measured using bioelectrical impedance analysis. A total of 4159 participants had sports participation data at age 10 years $(\mathrm{M}=10.32$ years, $\mathrm{SD}=4.68$ ).

Results From 3013 sport participants at age 10 years, $29.7 \%(n=894)$ had dropped out of sports at age 12 years. Of 2016 sport participants at age 12 years, $33.3 \%(n=705)$ had dropped out of sports by the age of 14 years. There were no differences in body fat percentage at any age according to differences in sport participation behaviours. Conclusions Based on a high prevalence, drop-out from organised extracurricular sports during childhood and adolescence may be an important public health behaviour to consider. A solution-oriented approach to dropout from organised sports is recommended, but more evidence as to potential health detriments is needed using high-quality research designs.

\section{INTRODUCTION}

Organised sports are among the most encouraged forms of physical activity in the pursuit of increased health and well-being in children and adolescents. ${ }^{1}$ Although the association between youth sport participation and paediatric obesity is unclear, ${ }^{2}$ recognised organisations $^{3-5}$ have advocated for the role of organised sports in this respect. However, there is evidence that drop-out from organised sports is association with health detriments. ${ }^{6}$ For example, children and adolescents who dropped out of organised sports reported lower physical activity, greater body fat and greater depression at age 20 than those who continued participation. ${ }^{7}$ Similarly, children who dropped out of organised sports between ages 8 and 10 reported lower health-related

\section{What are the new findings}

- There were no differences in body fat percentage at any age according to differences in sport participation behaviours.

- $33.3 \%$ of Australian youth had dropped out of sports between the age of 10 and 14 years.

- The rate of sport drop-out among Australian youth increased through transition.

quality of life and greater psychological difficulties at age $10 .^{89}$ The reasons for which children and adolescents drop out of sport include, but are not limited to injury, intrinsic pressures and pressure from other agents (eg, parents, coaches), inadequate resources and other social priorities. ${ }^{6}$

Furthermore, two systematic reviews have highlighted numerous problems with the methodology and quality of evidence within the field of drop-out from organised sports. ${ }^{610}$ For example, most studies are cross-sectional, and therefore, preclude an understanding of the health detriments that may result from drop-out. ${ }^{6}$ Additionally, population level monitoring of Australian sports participation typically proceeds by engaging repeated cross-sectional surveys. ${ }^{11} 12$ In this respect, the purpose of this study was to longitudinally examine dropout rates from organised sport and subsequent changes in body fat percentage as a function of dropout. First, we hypothesise drop-out from organised sports will increase with age. In addition, grounded in previous literature that supports the relationship between prolonged sport participation and lower body fat, ${ }^{6} 13$ we hypothesise that children who drop out of sports between the ages of 10 and 14 years will subsequently have higher levels of body fat compared with children who maintain participation. 


\section{METHODS}

\section{Procedures}

These data were collected from wave 4 (10 or 11 years of age), wave 5 (12 or 13 years of age) and wave 6 (14 or 15 years of age) of the Longitudinal Study of Australian Children (K cohort). For clarity, we refer to these ages as 10 , 12 and 14 years of age across waves 4-6, respectively. Data were collected using self-report questionnaires with the child's primary parent (the mother in $96 \%$ of cases). ${ }^{14}$ Informed consent was obtained from all participants.

\section{Measures}

Sport participation and dropout

Sports participation was measured using two parentreported items. Parents were asked 'In the last 12 months, has (your) child regularly participated in team sport (eg, football, cricket or netball)?', and subsequently, 'In the last 12 months, has (your) child regularly participated in individual sport (eg, tennis, karate or gymnastics)?' 'Regularly' was defined as at least once per week for 3 months or more (eg, a sports season). Parents could answer either 'yes' or 'no', and children were defined as participating in sports if parents answered 'yes' to at least one of the items. Children were thus categorised as (1) regularly participating in sports at both time points (eg, at both 10 and 12 years; 'participants'); (2) did not regularly participate in any sport at either time point ('non-participants'); (3) dropped out of sport between time 1 and time 2 ('dropouts') or (4) commenced regular participation in sport between time 1 and time 2 ('commencers').

\section{Body fat}

Participant body fat percentage was measured on digital scales using bioelectrical impedance analysis (BIA). Although issues regarding validity and measurement error do occur, BIA has proved to be a reliable and practical took to measure body fat in children and adolescents. $^{15}$

\section{Covariates}

Child sex, indigenous status, neighbourhood socioeconomic position (SEP), household-level SEP and language spoken at home were included as covariates. Neighbourhood SEP was determined according to the Socioeconomic Indexes for Areas Index of Relative Socioeconomic Disadvantage. ${ }^{16}$ Household-level SEP was measured using standardised household income. Household income was measured in dollars per week and was standardised to household size by dividing by the square root of the number of residents. ${ }^{17}$

\section{Statistical analyses}

Repeated measure analysis of covariance (ANCOVA) were used to examine associations between sports participation groups and body fat percentage across waves. First, we examined changes in body fat percentage as a function of sport participation groups between ages 10 and 12 (model 1). Subsequently, we examined associations between sport participation groups and changes in participant body fat across ages 10, 12 and 14 (ie, model 2). Finally, changes in body fat were examined as a function of sport participation groups between ages 12 and 14 (ie, model 3). We adjusted for all covariates in our models, and pairwise comparisons were performed post hoc in the event of a significant main effect.

\section{RESULTS}

\section{Participants}

This study included 4159 participants at age 10 (M age $=10.32$ years, $\mathrm{SD}=4.68), 3911$ at age $12(\mathrm{M}$ age $=12.41$ years, $\mathrm{SD}=4.92)$ and 3454 at age $14(\mathrm{M}$ age $=14.41$ years, $\mathrm{SD}=4.92$ ). Participants with complete data were more likely to be non-indigenous, and had parents who were older, more highly educated and spoke English at home. ${ }^{18-20}$ Study descriptives are reported in table 1 .

\section{Participation changes through transition}

Sport participation data were available at ages 10 and 12 years for a total of 3819 young people. In total, 3013 were sport participants at age 10, of whom 2119 (55.5\%) continued participation and 894 (29.7\%) dropped out of sport. Further, of the 2119 sport participants at age 12 years, 33.3\% $(n=705)$ had dropped out of all sports by the age of 14 years.

\section{Sports participation groups and body fat percentage}

With regard to model 1, ANCOVAs revealed a nonsignificant main effect of sports participation group for change of body fat percentage from age 10 to 12 years, $F(3,3113)=1.61, \mathrm{p}=0.17$. In model 2 , no significance emerged with regard to changes of participant body fat across ages 10,12 and $14, F(5.38,4596.44)=0.789$, $\mathrm{p}=0.57$. The assumption of sphericity was violated as indicated by a significant Mauchley's $W$. To accommodate this, the adjusted Huynh-Feldt Epsilon statistic was applied. ${ }^{21}$ Lastly, no significance emerged regarding changes in body fat percentage between ages 12 and 14, $F(3,2577)=1.06, \mathrm{p}=0.36$ (ie, model 3).

\section{DISCUSSION}

The purpose of this study was to report the prevalence of sport dropout and examine potential changes in body fat percentage over time as a function of sport dropout. A total of $29.7 \%$ of participants at age 10 had dropped out of sport by the age of 12 . In the subsequent 2 years, this equated to $33.3 \%$. In contrast to our hypothesis, there was no change in levels of body fat over time according to sport participation type at either 10-12 years of age or 12-14 years of age.

While drop-out rates among Australian youth sport participants have been estimated at around $30 \%,{ }^{11}$ they are often derived from studies that are methodologically flawed. For example, cross-sectional estimations of drop-out do not truly measure dropout behaviour ${ }^{22}$ and studies based within sports or sports clubs ${ }^{23}$ cannot account for those participants who simply transfer 


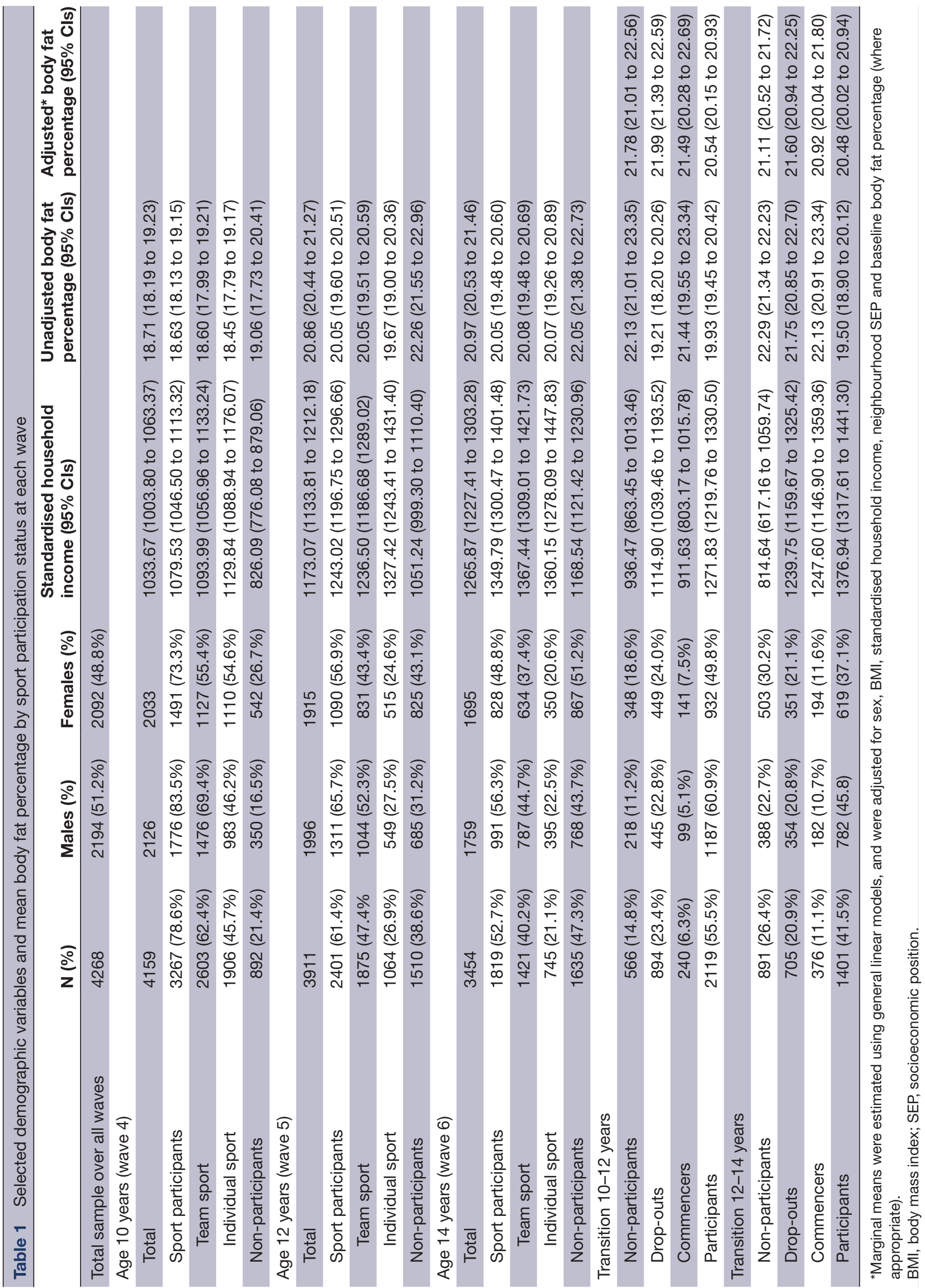


from one sport (or club) to another. The current study confirms that approximately $30 \%$ of all Australian youth sport participants dropped out of organised sports within a 2-year period. Thus, a drop-out rate of $30 \%$ in a highincome country represents many millions of children. Although non-participants commence organised sport at a similar rate to those who drop out, the number of youths who dropout exceeds the number commencing participation. Taken together, the exceeding number of dropouts in organised sport is worth consideration for the health and well-being of youth participants.

The drop-out rate from organised sports is significant for its magnitude, however, this study showed no change in levels of body fat over time. The evidence to support such a finding is equivocal. ${ }^{24}$ The novelty of this study was the within-subjects, repeated measures design which indicates that body fat did not change over time, regardless of one's sport participation behaviour. When compared with non-participants, the accumulated decrease of time spent in sport and increased caloric requirements during organised sport participation may account, in part, for the lack of individual change of body fat over time. ${ }^{24-26}$ Therefore, future interventions targeted to decrease childhood and adolescent obesity, specifically, may focus on physical activities outside of organised sport.

According to the behavioural epidemiology framework for health behaviour research, ${ }^{27}$ phase 1 is establishing associations between the health behaviour (eg, sport dropout) and outcomes (eg, obesity). However, this is in large part dependent on phase 2-developing methods for measuring behaviour. Thus, psychometrically sound measures of sports participation must be included in large, longitudinal studies. This would enable accurate estimates of the prevalence of dropout and any potential associated health detriments. Phase 3 includes establishing the factors that influence the health-related behaviour. However, two systematic reviews already point to a range of established intrapersonal, interpersonal and environmental factors that predict dropout from organised sports. ${ }^{610}$ As such, we recommend a solution-oriented approach be undertaken whereby the identification of the causes of dropout gives way to the identification of solutions to the problem. ${ }^{28}$

The strengths of this study include the within-subjects, repeated measure design and large longitudinal sample. Additionally, a valid measure of sports participation offered an accurate estimate of the prevalence of drop-out from organised sports and associations with body fat percentage. However, it is unclear whether dropout rates from organised sports reported herein are indicative of younger or older participants. Similarly, it is unclear if the lack of change in body fat percentage would remain consistent in alternate age ranges such as early adulthood. ${ }^{7}$

In conclusion, this study found that drop-out form organised sports is not associated with change in body fat percentage when compared with those who maintained sport participation and those who did not participate in sport. We recommend a solution-oriented approach to dropout from organised sport whereby experimental research and evaluation is undertaken that can be translated to public health policy and practice. We encourage longitudinal studies to continue monitoring the effects of changing sports participation behaviours on health outcomes while solution-oriented approaches are being implemented.

Acknowledgements The Longitudinal Study of Australian Children is conducted in partnership between the Department of Families, Housing, Community Services and Indigenous Affairs (FaHCSIA), the Australian Institute of Family Studies (AIFS) and the Australian Bureau of Statistics (ABS). They were responsible for the design and conduct of the study, and the collection and management of data. The findings and views reported in this paper are those of the authors and should not be attributed to FaHCSIA, AIFS or the ABS.

Contributors SAV: conceptualisation, formal analysis, writing and supervision. MJS: Conceptualisation, formal analysis and writing. JS: formal analysis and writing.

Funding The first author is supported by a National Heart Foundation of Australia Postdoctoral Fellowship (100974).

Competing interests None declared.

Patient consent for publication Not required.

Ethics approval This study was approved by the Australian Institute of Family Studies Ethics Committee.

Provenance and peer review Not commissioned; externally peer reviewed.

Data availability statement Data may be obtained from a third party and are not publicly available.

Open access This is an open access article distributed in accordance with the Creative Commons Attribution Non Commercial (CC BY-NC 4.0) license, which permits others to distribute, remix, adapt, build upon this work non-commercially, and license their derivative works on different terms, provided the original work is properly cited, appropriate credit is given, any changes made indicated, and the use is non-commercial. See: http://creativecommons.org/licenses/by-nc/4.0/.

ORCID iD

Jordan T Sutcliffe http://orcid.org/0000-0002-0636-7263

\section{REFERENCES}

1 World Health Organization. Global action plan on physical activity 2018-2030: more active people for a healthier world. World Health Organization, 2019.

2 Lee JE, Pope Z, Gao Z. The role of youth sports in promoting children's physical activity and preventing pediatric obesity: a systematic review. Behav Med 2018;44:62-76.

3 International Olympic Committee. Recommendations of theme: 'Olympism and Youth'. Paper presented at: XIII Olympic Congress. The Olympic Movement in Society, Copenhagen, 2009.

4 United Nations Inter-Agency Task Force. Sport for development and peace: towards achieving the millennium development goals. New York, 2003.

5 World Health Organisation. Promoting sport and enhancing health in European Union countries. Copenhagen: World Health Organisation, 2011.

6 Crane J, Temple V. A systematic review of dropout from organized sport among children and youth. Eur Phy Educ Rev 2015;21:114-31.

7 Howie EK, McVeigh JA, Smith AJ, et al. Organized sport trajectories from childhood to adolescence and health associations. Med Sci Sports Exerc 2016:48:1331-9.

8 Vella SA, Cliff DP, Magee CA, et al. Sports participation and parent-reported health-related quality of life in children: longitudinal associations. J Pediatr 2014;164:1469-74.

9 Vella SA, Cliff DP, Magee CA, et al. Associations between sports participation and psychological difficulties during childhood: a twoyear follow up. J Sci Med Sport 2015;18:304-9.

10 Balish SM, McLaren C, Rainham D, et al. Correlates of youth sport attrition: a review and future directions. Psychol Sport Exerc 2014;15:429-39. 
11 Sport Australia. AusPlay focus: Children's participation in organised physical activity outside of school hours. Canberra, 2018.

12 Seifert TA, Pascarella ET, Erkel SI, et al. The importance of longitudinal pretest-posttest designs in estimating College impact. New Directions for Institutional Research 2010;S2:5-16.

13 Vandendriessche JB, Vandorpe BFR, Vaeyens R, et al. Variation in sport participation, fitness and motor coordination with socioeconomic status among Flemish children. Pediatr Exerc Sci 2012;24:113-28.

14 Edwards B. Growing up in Australia: the longitudinal study of Australian children: the first decade of life. Family Matters 2012;91:7-17.

15 Talma H, Chinapaw MJM, Bakker B, et al. Bioelectrical impedance analysis to estimate body composition in children and adolescents: a systematic review and evidence appraisal of validity, responsiveness, reliability and measurement error. Obes Rev 2013;14:895-905.

16 Australian Bureau of Statistics. Information paper. An introduction to socio-economic indexes for areas (seifa) 2006. Catalogue No. 2039.0. Canberra: Australian Bureau of Statistics, 2008.

17 Australian Bureau of Statistics. AusStats 6523.0 household income and income distribution, Australia 2003-04 (appendix 3. Canberra, Australia: Australian Bureau of Statistics, 2005.

18 Daraganova G, Sipthorp M. Longitudinal study of Australian children: Isac technical paper No. 9: wave 4 weights. Melbourne, Australia: Australian Institute of Family Studies, 2011.
19 Cusack B, Defina R. The longitudinal study of Australian children: Isac technical paper No. 10: wave 5 weighting and non response. Canberra: Australian Institute of Family Studies, 2013.

20 Norton A, Monahan K. Growing up in Australia: the longitudinal study of Australian children: Isac technical paper No. 15. Canberra: National Centre for Longitudinal Data, 2015.

21 Allen P, Bennett K. SPSS Statistics-A practical guide. Cengage Learning Australia Pty Ltd, 2012.

22 Boiché JCS, Sarrazin PG. Proximal and distal factors associated with dropout versus maintained participation in organized sport. $J$ Sports Sci Med 2009;8:9-16.

23 Delorme N, Chalabaev A, Raspaud M. Relative age is associated with sport dropout: evidence from youth categories of French basketball. Scand J Med Sci Sports 2011;21:120-8.

24 Nelson TF, Stovitz SD, Thomas M, et al. Do youth sports prevent pediatric obesity? A systematic review and commentary. Curr Sports Med Rep 2011;10:360-70. doi:

25 Guagliano JM, Rosenkranz RR, Kolt GS. Girls' physical activity levels during organized sports in Australia. Med Sci Sports Exerc 2013;45:116-22.

26 Leek D, Carlson JA, Cain KL, et al. Physical activity during youth sports practices. Arch Pediatr Adolesc Med 2011;165:294-9.

27 Sallis JF, Owen N, Fotheringham MJ. Behavioral epidemiology: a systematic framework to classify phases of research on health promotion and disease prevention. Ann Behav Med 2000;22:294-8.

28 Robinson TN, Sirard JR. Preventing childhood obesity: a solutionoriented research paradigm. Am J Prev Med 2005;28:194-201. 